\title{
San Sebastian, vista por Paret y Alcázar
}

\author{
María Castilla Albisu* \\ View of San Sebastian by Paret y Alcázar
}

\begin{abstract}
RESUMEN:
ABSTRACT:

Luis Paret y Alcázar pintó una serie de vistas panorámicas de puertos del litoral Cantábrico, por encargo del rey Carlos III. El objetivo de este trabajo es ahondar en la vida de este pintor para así comprender

mejor su obra. A pesar de los estudios realizados por algunos historiadores quedan todavía incógnitas por descubrir relativas a la vida y al trabajo de este artista. Al acercarse a la figura de Paret y Alcázar hay que preguntarse por qué habiendo sido uno de los pintores más prometedores de su tiempo, su figura ha caído en un triste olvido.

Luis Paret y Alcázar painted a set of harbours of the Cantabric Coast in the north of Spain. Paret created this set of views to satisfy the commission of Carlos III, king of Spain.

The aim of this work is to go deeply into this painter's live, so that we can understand in a better way his art. Although the studies already done by several art historians, there are still a lot of unknown factors about his live and work. We should ask ourselves why he fell in the forgetfulness after being one of the rising painters at his time.

PALABRAS CLAVE: KEY WORDS:

Pintura, siglo XVIII, Paret y Alcázar, Paisaje, San Sebastián, vistas urbanas

Paint, XVIII century, Paret y Alcázar, Landscape, San Sebastián, urban views
\end{abstract}

\section{SAN SEBASTIAN, VISTA POR PARET Y ALCÁZAR}

Esta preciosa Vista de San Sebastián fue pintada por Luis Paret y Alcázar en 1786 y forma parte de la serie de puertos del litoral Cantábrico que realizó este pintor por encargo del rey Carlos III.

* Licenciada en Historia y en Informática. mcastilla@ bergara.uned.es 


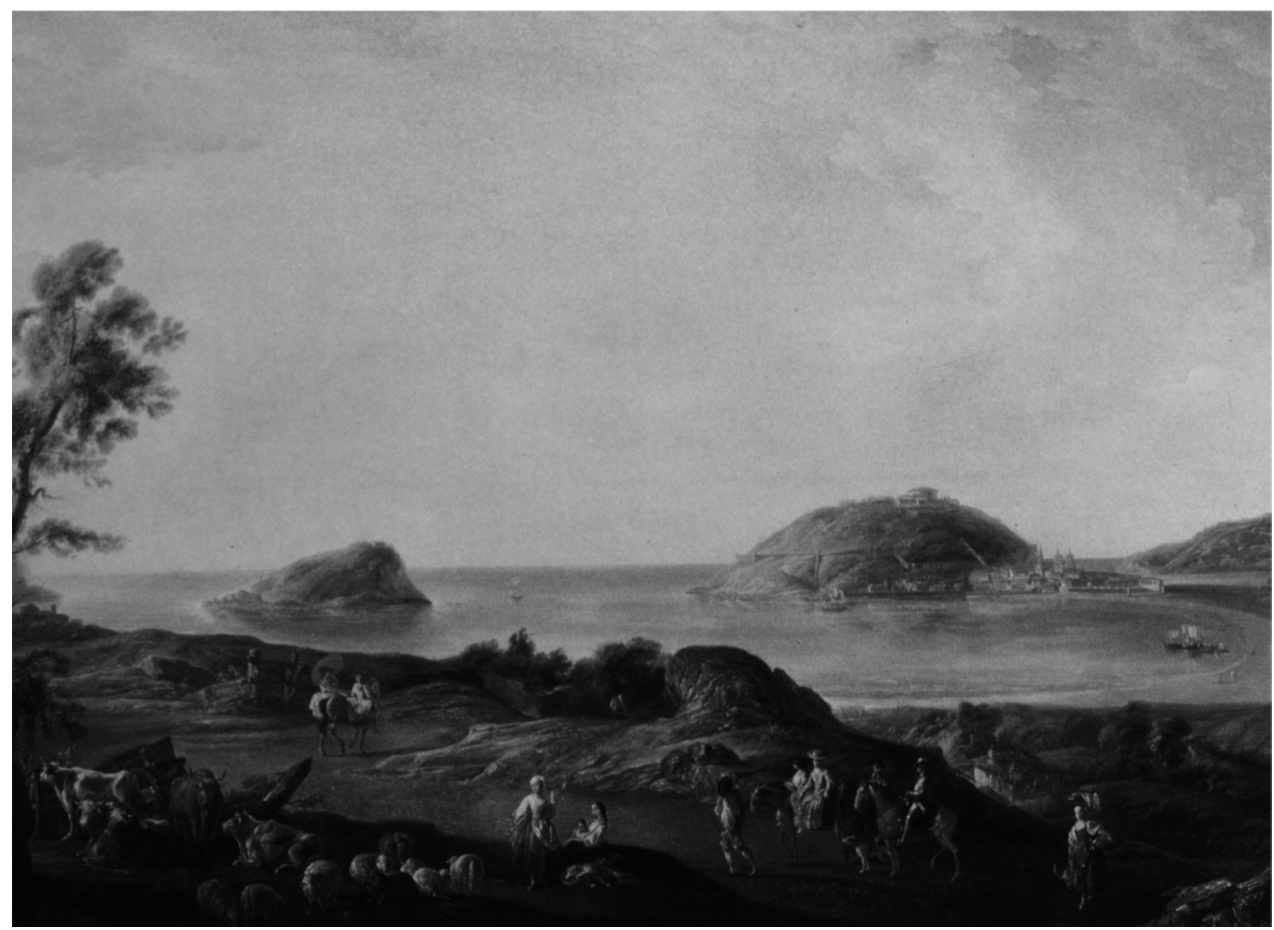

Fig.1. Luis Paret y Alcázar. Vista de San Sebastián. 1786

Antes de analizar la presente obra, convendría conocer algunos aspectos de la vida de Paret que influyeron de forma decisiva en su trayectoria artística: su formación, el exilio en Puerto Rico, su vida en el País Vasco o el propio encargo de la serie, son fundamentales para entender su obra.

Además, al acercarse a la figura de Paret y Alcázar hay que preguntarse por qué habiendo sido uno de los pintores más prometedores de su tiempo, su figura ha caído en un triste olvido. Quizá convendría empezar por ahí.

\section{Paret y Alcázar y el olvido}

A finales de 1775 el pintor Luis Paret y Alcázar dejaba atrás España y partía rumbo a Puerto Rico, lugar de destierro en el que pasaría casi tres años de su vida y que marcaría toda su trayectoria vital y pictórica. Los motivos de su destierro se analizarán más adelante, pero cabe decir que giran en torno a la relación que mantuvo con su protector, el infante don Luis de Borbón, hermano de Carlos III.

Paret, nacido en Madrid en 1746 y fallecido en el mismo lugar a la edad de 53 años, disfrutó de un comienzo artístico muy prometedor. Su contacto con el arte se remonta a los primeros años de su vida. Sus primeros maestros fueron el monje Bartolomé de San Antonio y el orfebre francés Agustín Duflos, joyero de Carlos III. Otro de sus maestros fue el también francés Jean François de La Traverse, alum- 
no del pintor rococó François Boucher y uno de los pintores que dejó más profunda huella en el estilo de Paret.

A una edad muy temprana ingresó en la Real Academia de Bellas Artes de San Fernando1, el paso por la Academia resultó determinante y siendo aun muy joven recibió sus primeros honores ${ }^{2}$. Además de pertenecer a la Academia en calidad de estudiante, en la última etapa de su vida ocupó en ella, un cargo directivo ya que fue nombrado en 1792 vicesecretario de la Junta de Arquitectura.

Paret completó su preparación artística con un viaje a Italia, viaje que se había hecho casi imprescindible en la formación de los artistas de la época. Fue el infante don Luis de Borbón quien se ofreció a costearle una pensión que le permitiera ampliar sus estudios en Roma.

A partir de 1766 se sitúa a Paret de vuelta en España. Desde el regreso de Italia y hasta que se produce su destierro, transcurren los años más fructíferos en la carrera artística del pintor. Durante esos años nos encontramos con el Paret más rococó. De este periodo son: Baile en máscara, La comida de Carlos III, Las Parejas Reales o La tienda del anticuario. Estos años de esplendor se truncan con el destierro a Puerto Rico.

El motivo del destierro no está claro, pero parece que tuvo que ver con la presunta colaboración del pintor en los asuntos amorosos del infante. Luis Paret se vio involucrado en este asunto, que con motivo o sin él, le llevó al exilio. Tampoco se descartan motivaciones políticas relativas a una supuesta aspiración del infante a la corona española y al temor de Carlos III a perder para sus hijos el derecho a la sucesión.

Quien fuera su protector, el infante Luis de Borbón, fue el responsable indirecto de su destierro y por lo tanto de su alejamiento de la Corte, lo que supuso un freno en su carrera ya que era prácticamente imposible en aquella época seguir una trayectoria artística de cierto nivel fuera del entorno cortesano.

Poco se conoce de la vida de Paret en Puerto Rico. En la isla siguió pintando; así lo atestigua su Autorretrato (h. 1776) en el que se representa con indumentaria isleña. Sabemos además que fue maestro de José Campeche, uno de los pintores más importantes que iba a tener Puerto Rico.

\footnotetext{
${ }^{1}$ Según Rosario Peña «Paret fue inscrito en ella (en la Academia) en octubre de 1757 cuando contaba con algo más de once años de edad.». PEÑA, Rosario, «El infante don Luis de Borbón y Luis Paret y Alcázar», Luis Paret y Alcázar 1746-1799, Vitoria, Servicio Central de Publicaciones del Gobierno Vasco, 1991, pág. 68.

2 «... a la academia de San Fernando, la que le adjudicó el segundo premio de la segunda clase en 760 y el primero de la [segunda clase] misma en 66.», CEAN BERMUDEZ, Juan Agustín, Diccionario histórico de los más ilustres profesores de las Bellas Artes en España, Madrid, Imprenta viuda de Ibarra, 1800, tomo IV, pág. 53.
} 
Transcurridos casi tres años Paret recibió la noticia de que su pena de destierro había sido conmutada por la de alejamiento de la Corte y de los Reales Sitios. Por fin, podía volver a España.

Este destierro y posterior alejamiento de la Corte fue muy negativo para su carrera, ya que cuando Paret regresó a España, el panorama con el que se encontró era diferente al que había dejado al partir de Madrid. Goya ya estaba situado como pintor cortesano y cosechaba importantes éxitos, con sus cartones para la Real Fábrica de Tapices de Santa Bárbara.

La entrada de Peret en el mundo del arte, sus éxitos tempranos en la Academia y el hecho de que fuera un pintor original de reconocida erudición y con muy buena mano para el dibujo, auguraban un futuro exitoso al joven pintor. La realidad no fue así, ¿ por qué este pintor cayó en el olvido? Podríamos analizar varios motivos.

Paret y Goya nacieron el mismo año, con pocos meses de diferencia, El hecho de ser contemporáneos y desarrollar su carrera de forma paralela, dejó a Paret a la sombra del gran maestro. La grandeza de Goya eclipsó a los pintores de su época.

Por otra parte, el gusto rococó del primer Paret, alejado del neoclasicismo dominante de la época y sus circunstancias personales que le llevaron al destierro fuera de España, le alejaron de los círculos artísticos más relevantes del momento.

La valía, pero también, la fortuna, las circunstancias de la vida, la moda pasajera, el capricho de algún mecenas,...; muchos factores influyen en la fama o en el olvido de un artista. El protector que en un momento de la vida ayuda y da un impulso a la trayectoria artística de una persona, puede ser en otra etapa el causante, quizás involuntario, de su caída.

En el caso de Paret y Alcázar quien fue su protector, el infante Luis de Borbón, convertido en su valedor en un primer momento y gracias a quien Paret pudo realizar el viaje de estudios a Roma, fue en definitiva el responsable indirecto de su destierro y por lo tanto de su alejamiento de la Corte lo que incidió negativamente en su carrera.

Muchos estudiosos consideran a Luis Paret como uno de los mejores pintores de su periodo y el mejor representante del rococó español, pero desgraciadamente y como ha ocurrido a lo largo de la historia, un pintor además de su genio tiene que tener fortuna y quizás esta carencia derivó en este olvido.

Es cierto que Paret y Alcázar hoy en día no es un pintor muy conocido y sin embargo llama la atención saber, que una obra suya aparece con frecuencia en televisión, cuando se transmiten las audiencias del rey. Se trata de esta obra, Vista de San Sebastián, que pertenece a Patrimonio Nacional y forma parte de la «Serie de puertos de la mar Océana», pintada por encargo de Carlos III.

Esta vista de San Sebastián se encuentra en la Sala de Audiencias del Palacio de la Zarzuela. Anteriormente estuvo ubicada en el Palacio Real de Madrid, hasta 
que, por deseo del rey Juan Carlos I, se trasladó al citado palacio³. Quizá el rey añoraba la vista de la Concha, que desde el Palacio de Miramar, veía durante los veranos de su infancia.

\section{El regreso al País Vasco}

Tras los años de destierro, en 1778 Luis Paret regresó a España. La pena de destierro le fue conmutada por una de alejamiento que le obligaba a residir a una distancia mínima de cuarenta leguas de la Corte $^{4}$. Así fue cómo el pintor recaló en el País Vasco; aquí aguardaría el ansiado perdón que le permitiese regresar a la Corte.

Paret se instaló en Bilbao y en esta villa permaneció entre los años 1778 y $1786^{5}$. En 1785 tras la muerte del infante don Luis, Paret solicitó el perdón de su pena de alejamiento. En noviembre de ese mismo año recibía la feliz noticia de que el rey, Carlos III, le permitía regresar a Madrid. Logrado el perdón, todavía permanecería un tiempo en el País Vasco realizando diversos encargos.

En 1780 Paret fue nombrado académico de San Fernando ${ }^{6}$. Este nombramiento sumado a su ya ganado prestigio como pintor, le ayudó a conseguir encargos tanto en Bilbao como en Viana (Navarra). Precisamente en esta segunda localidad, en la capilla de San Juan del Ramo de la iglesia de Santa María, realizó el programa pictórico de temática religiosa más ambicioso de toda su carrera. Su obra fue acogida con agrado, lo que le abrió la puerta a nuevos trabajos.

Los encargos que se solicitaban a Paret eran obras de muy distinto tipo, desde pintura hasta trazas para altares o diseños arquitectónicos para fuentes. Estas labores no estrictamente pictóricas, si bien son muestra de la capacidad y del espíritu polifacético de Paret, también son el testimonio de la diversidad de encargos que se vio obligado a acometer en un entorno que a pesar de haberle recibido de muy buen grado, no disfrutaba del nivel adquisitivo y artístico del de la clientela cortesana que pudiera haber tenido en Madrid.

\footnotetext{
3 «Durante muchos años ha estado en el Palacio Real, Madrid. Recientemente (1986), por deseo de Su Majestad Juan Carlos I, fue trasladado junto con el Puerto de Pasajes a la Sala de Audiencias del Palacio de la Zarzuela, Madrid». GONZALEZ DE DURANA, Javier, BARAÑANO Kosme, «Puertos Vascos en la obra pictórica de Luis Paret y Alcázar» en Anuario 1986 Estudios - Crónicas, Museo de BBAA de Bilbao, Bilbao, Ediciones Comerciales, 1987, pág. 35

${ }_{4}$ «El 22 de mayo de 1778 el Consejo de Castilla le conmuta la pena por un alejamiento de cuarenta leguas de la Corte». SANCHEZ CANTON, Francisco Javier, Ars Hispaniae, Escultura y pintura del siglo XVIII, Francisco Goya, Madrid, Plus Ultra, 1958, pág. 237.

5 «Su presencia en Bilbao durante los cerca de ocho años (1778-86)», GONZALEZ DE DURANA, Javier, «Vista de Fuenterrabia», en Luis Paret y Alcázar y los puertos del País Vasco, Bilbao, Museo de Bellas Artes de Bilbao, 1996, pág. 28.

${ }^{6}$ «Desde allí (Vizcaya) dirige a la Academia el memorial de 12 de marzo de 1780, para que le concedan el entrar en ella». SANCHEZ CANTON, Francisco Javier, Op. Cit., pág. 237.
} 
En Bilbao Paret estuvo relacionado con el mundo ilustrado de la villa. No olvidemos que en 1765 se había fundado la Real Sociedad Bascongada de los Amigos del País. Esta sociedad se creaba con la vocación de impulsar los estudios de economía y de estimular la creación de programas reformistas en ciencia y educación ${ }^{7}$. Fue la primera sociedad de estas características fundada en España y no tardó en obtener el respaldo y protección del monarca y el apoyo del mundo ilustrado. Intelectuales, artistas, escritores y nobles, encontraron en esta sociedad un lugar adecuado para desarrollar su trabajo.

Paret tuvo contacto con las élites ilustradas de Bilbao; Se relacionó con algunos miembros de la Sociedad Bascongada, entre ellos José Santiago Ruiz de Luzuriaga, médico y miembro de la sociedad en la que fue profesor.

También mantuvo contacto con José María de Aguirre, V marqués de Montehermoso, socio fundador de esta sociedad y miembro de la Real Academia de Bellas Artes de San Fernando, en la que en 1756 había sido nombrado académico de mérito y de honor ${ }^{8}$.

Y otra relación que ligó a Paret con esta sociedad fue la que le unió a Joaquín Hurtado de Mendoza, conde de Villafuente Bermeja, coleccionista de arte y dueño, en su día, de la vista de Portugalete y de la vista del Arenal de Bilbao que formaban parte del conjunto de vistas marítimas de Luis Paret.

En 1786 ponía fin a su estancia en el País Vasco y regresaba a Madrid. Allí pudo volver a incorporarse al círculo artístico cortesano.

\section{Encargo de la serie}

El 4 de julio de 1786 Carlos III encargó a Luis Paret que pintara una serie de puertos del litoral Cantábrico.

Actualmente se conocen nueve «vistas» de puertos del Cantábrico aunque no podemos descartar que haya más. Cinco corresponden a Vizcaya: dos del Arenal de Bilbao, una de Portugalete, una de Bermeo y otra de Olaveaga; y cuatro a Guipúzcoa: una de San Sebastián, una de Pasajes y dos de Fuenterrabia.

\footnotetext{
7 «Los fundadores de la REAL SOCIEDAD BASCONGADA DE LOS AMIGOS DEL PAÍS, tuvieron como objetivo el cultivo y fomento de cuantas materias, artes, disciplinas, ciencias, actividades literarias, sociales y humanas pudiesen enriquecer los conocimientos vigentes en la época y por ello encuadraron sus actividades en comisiones de agricultura y economía rústica, artes y ciencias útiles, actividades industriales y comerciales y política y buenas letras, disciplinas a desarrollar con criterios pragmáticos y de utilidad.», www.bascongada.org, pág. 1.

${ }_{8}$ «A través de las relaciones de Aguirre con los artistas de la Academia de San Fernando la Bascongada debió de contratar alguna obra más. Este pudo ser el caso de Luis Paret. Suyo es el dibujo del retrato del conde de Peñaflorida grabado en Madrid por Manuel Salvador Carmona en 1785.». BLANCO MOZO, Juan Luis, "Varia paretiana», I CONGRESO INTERNACIONAL PINTURA ESPAÑOLA SIGLO XVIII, Marbella, Museo del grabado español contemporáneo, 1998, pág. 314.
} 
Este tipo de vistas en las que se buscaba presentar la geografía local fue bastante común en esta época. Cabe reseñar la obra que Vernet realizó por encargo del rey Luis XV sobre puertos del litoral francés o la obra de pintores como Mariano Ramón Sánchez o el mismo Luis Paret en España.

Esta moda no fue un fenómeno novedoso. En épocas anteriores también la monarquía había coleccionado imágenes de ciudades ligadas al territorio que gobernaba. En España Anton van den Wyngaerde representó un importante número de vistas de ciudades españolas por encargo de Felipe II. Desgraciadamente muchas de ellas desaparecieron en incendios como el que devastó el Alcázar de Madrid. Estas vistas urbanas además de una finalidad decorativa, tenían la importante misión de ligar la imagen del poder de la monarquía a la de los territorios que dominaba. No sólo en España, también en otras cortes europeas, a partir del Renacimiento, fue habitual que los monarcas decorasen las galerías de sus palacios con las vistas de las ciudades sobre la que ejercían el poder.

A tenor de los grabados que poseía, parece claro que Paret conocía las marinas de Vernet $^{9}$ y al igual que éste, optó por recrear los paisajes basándose en la observación de la naturaleza y no en la utilización de elementos paisajísticos preconcebidos.

Paret realiza en esta serie de vistas panorámicas un trabajo muy bien terminado y muy personal, obteniendo como resultado un conjunto homogéneo y de gran calidad artística, en la línea rococó que él dominaba ${ }^{10}$, y logrando además un gran realismo en la representación del lugar, convirtiendo la obra en un documento gráfico. Paret no se limitó a proporcionar una fría descripción geográfica, sino que se preocupó de plasmar en ellas sus ideales estéticos, obteniendo así, unas obras de gran belleza.

El encargo de Carlos III contó con el compromiso de Paret de entregar dos cuadros al año ${ }^{11}$. Este encargo le iba a proporcionar al pintor 15.000 reales anuales y esta asignación se prolongaría hasta el año 1792, es decir, años después de la muerte del monarca. Teniendo en cuenta que la serie se comenzó en 1786 y se

\footnotetext{
9 «En el inventario de su biblioteca constan abundantes obras de autores clásicos, algunas en versión original, y también álbumes de grabados, particularmente de obras de Hogarth, Bourdon, Stubbs, Vernet y Guercino.». BRAY, Xavier, www.museodelprado.es/enciclopedia/enciclopedia-on-line/voz/paret-y-alcazar-luis/. pág. 1.

10 «Paret pintó vistas de San Sebastián y de Fuenterrabia, de Pasajes, Bermeo, etc., en las que se unen lo pintoresco del paisaje y los personajes, siempre en escala reducida, con la amplitud del firmamento, el énfasis en la atmósfera y el carácter un tanto artificioso de la vegetación, cuando la hay, o de las rocas playeras y marinas. La valoración de estas pinturas rococó en fecha tan tardía como los años ochenta pone de relieve la amplitud de los criterios de gusto y la vigencia de un estilo que podía parecer históricamente agotado.» BOZAL, Valeriano, Goya. Entre Neoclasicismo y Romanticismo, Historia del arte historia 16 - Grupo 16, Madrid, 1989, pág. 28.

11 «En el mismo año de 1786, el 4 de julio, Carlos III le comisiona para pasar con quince mil reales anuales a los puertos de la Cantabria a trazar planos y vistas de ellos, debiendo entregar por lo menos dos obras cada año.». DELGADO, Osiris, Paret y Alcázar, Madrid, Universidad de Puerto Rico Instituto Diego Velázquez del C.S. de I.C. y Universidad de Madrid, 1957, pág. 36.
} 
finalizó en 1792 y que Paret tenía el compromiso de entregar dos vistas por año, cabe pensar que Paret pudo haber pintado más vistas que las que hoy se conocen.

Por otra parte se cree que en 1783 Paret ya había pintado varias vistas de la ría de Bilbao, lo cual induce a pensar que estas vistas las comenzase a pintar por su propia cuenta antes de la comisión de Carlos III. También se contempla la posibilidad de que alguna de estas vistas fuera pintada y vendida a algún industrial o comerciante bilbaíno, lo cual reforzaría la hipótesis que contempla la existencia de más vistas, hoy en día desconocidas.

En este sentido, el historiador José Manuel de la Mano sostiene que no todas las vistas de la colección de Paret pertenecen al encargo realizado por Carlos III. En su opinión sólo pertenecen las de mayores dimensiones, las otras habrían tenido como destino colecciones de clientes particulares; el conde de Villafuente Bermeja, o el propio Príncipe de Asturias, para quien habría estado destinada la Vista de Bermeo ${ }^{12}$. De la Mano llega a esta conclusión tras determinar que el número 215 escrito en esta pintura, se corresponde con la obra El puerto de Bermeo que aparece en el inventario de las pinturas de la casita de El Escorial. También Gónzalez de Durana y Kosme Barañano consideran que algunas obras fueron realizadas por Paret antes de recibir el encargo real ${ }^{13}$. Otros autores, sin embargo, consideran que las nueve vistas conocidas pertenecen en su totalidad al citado encargo.

En el año 1996, el Museo de Bellas Artes de Bilbao organizó una exposición en la que se produjo un hecho sorprendente. Se descubrió que dos obras de Luis Paret consideradas hasta entonces independientes, formaban parte de un todo. $\mathrm{El}$ cuadro Vista de Fuenterrabia 44,3 x 57,2 y el cuadro Escena de aldeanos 48,3 x 37 , eran dos fragmentos de una misma obra que, en el pasado había sido dividida en dos partes. No solo se descubrió que estas obras formaban parte de un todo, sino que además, este todo era mayor que la suma de las dos partes. Sus dimensiones originales debieron de ser 73,66 x 116,84, es decir, un tamaño cercano al de 82 x $120 \mathrm{~cm}$., correspondiente a las otras vistas guipuzcoanas ${ }^{14}$. Otro dato in-

\footnotetext{
12 «Hasta hace poco tiempo se pensaba que todas estas vistas marítimas esbozadas por Paret integraban un mismo llamamiento palatino. Sin embargo, aparte de las que se compusieron con destino a Carlos III entre 1786 y 1788, que corresponderían a las de mayor tamaño, el pintor plantearía otras para clientes privados, como el conde de Villafuente Bermeja, y otras, como sucede con esta panorámica de Bermeo, rumbo a la colección del Príncipe de Asturias». DE LA MANO, José Manuel, «Luis Paret y Alcázar», Carlos IV mecenas y coleccionista, Madrid, Patrimonio Nacional, 2009, pág. 238.

13 «Sin embargo, Paret antes de esa fecha ya tenía realizadas algunas de esas vistas, las dos de $\mathrm{El}$ Arenal de Bilbao, la de Luchana y la de Bermeo, pues corresponden a los años 1783, 1784 y 1785, de tal manera que, como mucho, quedan seis cuadros conocidos restantes como resultado directo del encargo». GONZALEZ DE DURANA, Javier, BARAÑANO Kosme, Op. Cit, pág. 21.

${ }_{14}$ «...Estas eran las suposiciones que permitían conjeturar los dos fragmentos existentes, sin más información sobre ellos. No obstante, dichas conjeturas se convirtieron en hechos tras el descubrimiento del siguiente dato: en la subasta celebrada por Thomas Birch, Jr. (Bordentown, New Jersey), en 1845, de una parte de los fondos que habían pertenecido a la colección de arte de Jose Bonaparte, figura una pintura de Paret descrita del siguiente modo: «Paret, 1786.- Landscape: walled City in the distance, Figures, Sheep, \& c. in the foreground; a charming Picture. C. $3 \mathrm{ft} .10 \mathrm{in}$. L. by $2 \mathrm{ft} .5 \mathrm{H}$. (...). Traduciendo al sistema métrico decimal, la pintura medía entonces 73,66 x 116,84 cm., dimensiones muy aproximadas, por
} 


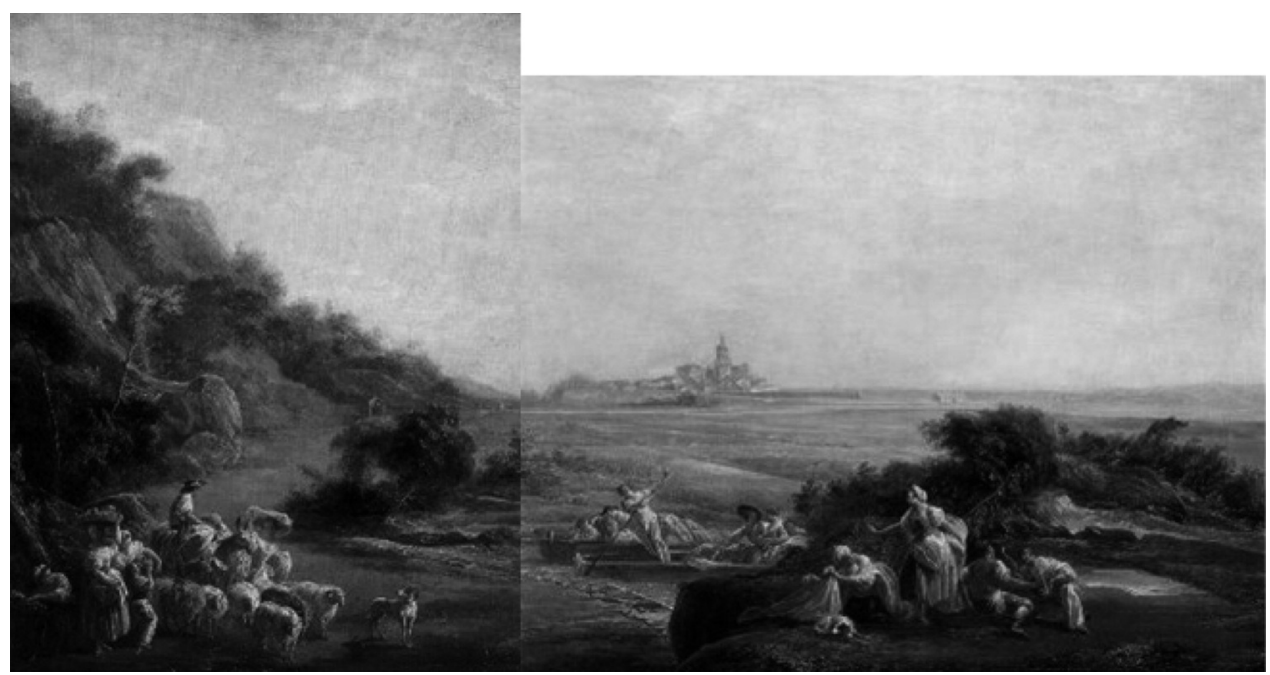

Fig.2. Luis Paret y Alcázar. Vista de Fuenterrabia. 1786-89

teresante relativo a esta obra es el de haber pertenecido, según parece, a la colección de obras de arte que José Bonaparte se llevó de España.

Este descubrimiento abrió la puerta a nuevas investigaciones y de esta forma se dedujo que el cuadro Marina con figuras 70 x 75 del Museo Cerralbo de Madrid, en el que se representaba un lugar sin identificar, se correspondía con una vista de Portugalete y que por lo tanto pertenecía a la serie de vistas de los puertos del País Vasco y que al igual que Vista de Fuenterrabia, habría sido fragmentada en un momento posterior a su creación ${ }^{15}$. De esta forma el formato prácticamente cuadrado de la vista de Portugalete, que no encajaría con las dimensiones de las otras vistas del encargo, podría haber tenido hipotéticamente un tamaño similar al del resto de obras.

Resumiendo, nos encontramos por lo tanto, ante dos hipótesis distintas: una primera que contempla que las nueve vistas conocidas forman parte del encargo de Carlos III, faltarían por localizar cinco vistas, correspondientes a las dos por año que supuestamente realizó Paret entre 1786 y 1992; y, otra segunda según la cual, no todas las vistas conocidas, es decir las nueve, formarían parte del encargo, sino que algunas de ellas habrían sido realizadas para clientes privados. En ambas hipótesis cabe la suposición de la existencia de otras vistas de puertos, ajenas al encargo real y pintadas para clientes privados.

tanto, a las convencionales de las «vistas» guipuzcoanas, casi todas ellas de $82 \times 120 \mathrm{~cm}$.». Museo de BBAA de Bilbao, Luis Paret y Alcázar y los puertos del País Vasco, Bilbao, Museo de BBAA de Bilbao, 1996, págs. 35-36.

15 « ¿La mano mutiladora fue la misma en la Vista de Fuenterrabía y en la Vista de Portugalete? ¿cuándo se produjeron las mutilaciones? (...) Poco se puede aclarar acerca de esto, pero, en cualquier caso, todo lo que se conjeture tiene que ver con la dispersión que la serie de pinturas sufrió durante la Guerra de la Independencia contra Francia.». Ibídem, págs. 35-36. 


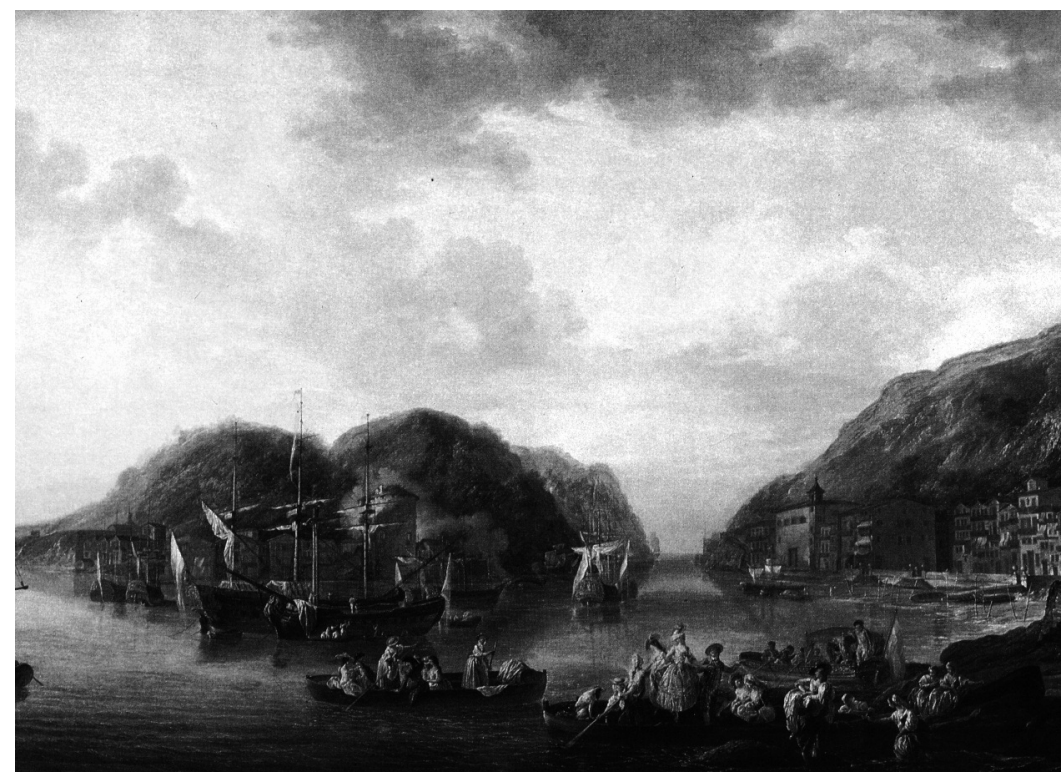

Fig.3. Luis Paret y Alcázar. Vista de Pasajes. 1786

La homogeneidad en las dimensiones de las vistas guipuzcoanas (las cuatro son cercanas a $82 \times 120 \mathrm{~cm}$ ) confirmarían su pertenencia a la serie. Las dudas se centrarían en las vizcaínas: Arenal 73 x 109; Arenal 60,3 x 83,2; Portugalete 70 x 75; Olaveaga 63,7 x 94 y Bermeo 60,3 x 83,2.

Con respecto al grupo de obras que no fueron encargadas por el rey pero que coinciden en la temática portuaria, existe por lo menos una vista de un puerto del País Vasco, Vista de Luchana, dibujo realizado a plumilla y tinta sobre papel, firmada, dedicada y datada en 1785. Actualmente se encuentra perdida. El hecho de que esté dedicada al señor Josef Patrás, amigo del pintor, hace pensar que no formaba parte de la serie ${ }^{16}$.

En esta serie marítima Luis Paret realizó una crónica de su tiempo, mezcló la imagen de personas que se esforzaban en los duros trabajos portuarios, con la de los apacibles paseos de miembros de la alta sociedad compartiendo un mismo espacio. La dureza del trabajo y la placidez de la vida relajada reflejaban la dualidad de una sociedad que no tardaría en alzarse contra estos privilegios y evolucionaría hacia un nuevo modelo que iba a dejar atrás el Antiguo Régimen e iba a aspirar a eliminar las diferencias sociales debidas al nacimiento. Pero estos cambios todavía no habían llegado y Paret representó a esa sociedad y con voluntad narrativa se

16 «(La vista de Luchana) sólo se conoce su imagen (procedente de un archivo de documentación británico), que fue realizado en 1785 y que estaba dedicado a un amigo llamado Josef Patras. Esta dedicatoria, obviamente, excluye el dibujo como parte del encargo real.».ldem, pág. 40. 
convirtió en un magnífico cronista histórico.

En estas pinturas de Paret se refleja la sociedad del momento. La manera en la que el pintor representó la geografía y la actividad laboral hay que entenderla en el contexto de la llustración. Paret supo reflejar en sus obras una visión utilitaria y práctica de la sociedad, plasmada en las escenas que recogían el trabajo manual de los trabajadores de los puertos. Los ilustrados insistían en la necesidad del trabajo como forma de progreso para el país y criticaban la cantidad de personas, que por unos u otros motivos no trabajaban. Esta serie recreaba perfectamente estos aspectos económicos y además aportaba, de forma rigurosa, una imagen de la geografía de las costas españolas ${ }^{17}$.

A diferencia de lo que ocurría en otros países europeos, véase Holanda, la pintura española, en el siglo XVIII, carecía de una significativa tradición paisajista. Tomando este aspecto en consideración, el paisaje paretiano adquiere más valor por lo que supone de innovación en cuanto a la elección del género pictórico.

El paisaje comenzó a tener una mayor presencia en España a partir del siglo XVIII, con la pintura de los cartonistas de la Real Fábrica de Santa Bárbara. En los cartones abundaban las escenas costumbristas en las que el paisaje no era el motivo principal sino una referencia espacial, necesaria para situar a los personajes que componían la escena. Esta forma de crear el paisaje y después colocar en él las figuras, proporcionaba un resultado un tanto artificioso. Se utilizaban convencionalismos como representar un espacio paisajístico preestablecido no real, o copiar paisajes ya realizados, por ejemplo de estampas flamencas.

La afición a la caza de Carlos III Ilevó a los cartonistas a introducir la temática cinegética que lógicamente estaba enmarcada en paisajes. El gusto por los paisajes y por la representación de la naturaleza se fue incorporando paulatinamente en las escenas costumbristas de los tapices.

En el género del paisaje Paret introdujo novedades frente a aquellos paisajes subordinados a la escena, copias en ocasiones de paisajes lejanos o desconocidos. El pintor abordó sus paisajes de forma realista, tomó la naturaleza como modelo y la reprodujo de la forma más fiel posible. Consiguió así, representar paisajes reales, dar vida a todo el conjunto y transmitir una imagen fidedigna del lugar, un lugar que cualquiera que lo visitase pudiese reconocer.

En 1787 Paret abandonaba el País Vasco; regresó a Madrid y se llevó apuntes y bocetos, que le iban a permitir finalizar la serie en la capital. Dicha serie se destinó a la Casita del Príncipe de El Escorial y allí permaneció hasta que José Bonaparte y las tropas napoleónicas expoliaron, entre otras obras, estas vistas que se

\footnotetext{
17 «Así, el concepto postulado por la llustración de educar al pueblo - que es una de las aportaciones más características y sobresalientes de la época- se hizo extensible a las artes figurativas en su calidad de lenguaje, de medio de comunicación. (...). Hay por consiguiente una aproximación entre estética y ética.». GARCIA MELERO, José Enrique, Arte español de la llustración y del siglo XIX. En torno a la imagen del pasado, Madrid, Ediciones Encuentro, 1998, pág. 104.
} 
cree que prácticamente en su conjunto formaron parte del «equipaje» del rey que salió del país ${ }^{18}$.

\section{Vista de San Sebastián}

Esta vista que fue pintada hacia el año 1786; pertenece; como se ha indicado, a la serie que Paret realizó sobre los puertos del mar Cantábrico. Este cuadro junto con el de Pasajes fue expuesto en San Sebastián en 1964 según se desprende de un artículo publicado en un boletín municipal de este año ${ }^{19}$.

Los dos cuadros de Paret formaban parte de una exposición constituida por tesoros del Patrimonio Nacional, en la que se expusieron armaduras, arneses, tapices, alfombras y cuadros. Además de las dos obras de Paret mencionadas, se expusieron cuadros de Goya y de otros pintores del siglo XVIII como Maella y los Bayeu ${ }^{20}$.

La exposición fue organizada por la institución del Patrimonio Nacional y contó con la colaboración del Ayuntamiento de la ciudad. Esta exposición se realizó en el Museo Municipal de San Telmo, antiguo convento de dominicos. Era práctica habitual, por aquellas fechas, la celebración de importantes exposiciones anuales en este museo que hoy está de actualidad por haber sido objeto de una ambiciosa reforma que lo ha transformado considerablemente.

La vista de San Sebastián está pintada con la perspectiva del Alto de Miraconcha. Como bien se apunta en el citado artículo el pintor se permitió ciertas licencias; véase la extraña forma de la isla, que permite suponer que el autor realizó el trabajo en el estudio en base a apuntes tomados del natural. A pesar de ello, el conjunto se ajusta bastante a la realidad del paisaje. Se representa la bahía de la Concha y la isla Santa Clara, el monte Urgull majestuoso con sus murallas, y el castillo de Santa Cruz de la Mota en su cima; tras el monte, se aprecia la entrada a la Zurriola y en la lejanía, Ulía. También se divisa el puerto pesquero donostiarra bien abrigado por el monte Urgull y las torres barrocas de la parroquia de Santa María.

\footnotetext{
18 «A pesar de haber figurado hasta 1927 en propiedad de un coleccionista bilbaino, nada nos impide creer que las dos «vistas» de El Arenal, así como la de Bermeo, formaran parte de la colección en El Escorial y que, años después, por avatares diversos regresaron a Bilbao, de donde volvieron a salir camino de las islas británicas y de Cataluña. De hecho, nada se sabe con exactitud de cuántas y cuáles eran las «vistas» que se encontraban en la Casita del Príncipe antes del expolio napoleónico, habiéndose dado por hecho siempre que todas las «vistas» conocidas estuvieron con seguridad en la Casita, lo que muy bien pudo no haber sido así. «. Museo de BBAA de Bilbao, Op. Cit., págs. 40-41.

19 «..., permítasenos referirnos particularmente a dos pequeños lienzos del pintor Luis Paret, (...), uno de ellos una vista de San Sebastián, (...), y el otro, una vista del puerto de Pasajes, (...)». Biblioteca Koldo Mitxelena (KM), Boletín de información municipal San Sebastián, Año 6, n.22-24, pág.67, 66322, «Una vista de San Sebastián, por el pintor Luis Paret: (s. XVIII)», abril-diciembre de 1964.

20 «Este último verano, en efecto, tuvo lugar en él (Museo Municipal de San Telmo) la primera exposición de riquezas artísticas del Patrimonio Nacional, ....magníficos tapices flamencos y españoles y las alfombras de nudo (...), así como los esplendidos cuadros, retratos, y paisajes de Goya y de Vicente López, de los Mallea, los Baye y los Madrazo, (...)». Ídem.
} 
San Sebastián era una ciudad volcada al mar. Su puerto era de vital importancia para el comercio y la pesca. Esta cercanía al mar se convertía en una estupenda vía de comunicación con el norte de Europa que desde tiempo atrás fue deseada por navarros y castellanos como salida al mar. Parece que tanto el castillo de la Mota como las murallas de la ciudad fueron erigidos por Sancho El Mayor en el siglo $\mathrm{XI}^{21}$; en el siglo XII otro rey navarro, Sancho el Fuerte reforzaría las murallas. Más adelante, en el año 1200, la ciudad pasaría a formar parte del reino de Castilla.

El articulista del boletín municipal mencionado aporta un dato que conviene remarcar: se trataría según él, de la presencia en el cuadro del torreón del faro, que permitiría situar la obra cronológicamente en un escenario posterior a $1778^{22}$. Este torreón del faro fue erigido en el monte Arrobi, primer monte de la pequeña cordillera de Igueldo, en el año 1778. La construcción fue llevada a cabo por el Consulado Donostiarra que en esa fecha contaba ya con casi un siglo de vida. El Consulado y Casa de Contratación de San Sebastián se creó en el año 1682; fue el 13 de marzo cuando se emitió una real cédula, expedida por Carlos II, que concedía el permiso para la creación de este Consulado. Uno de los objetivos de los promotores fue el de reforzar y revitalizar el comercio de la provincia. Hubo alguna reticencia por parte de las Juntas Generales ya que consideraban que podía poner en peligro su jurisdicción, pero finalmente se llevó adelante y se creó este Consulado.

El actual Museo Naval que se encuentra a los pies de Urgull en uno de los muelles del puerto, fue sede del Consulado ${ }^{23}$ y aparece representado en la pintura. Es uno de los pocos edificios que se salvó de la destrucción de la ciudad el 31 de agosto de 1813. Se cree que fue edificado hacia mediados del siglo XVIII pero se desconoce la fecha exacta ya que en el devastador incendio producido en esa fecha, desaparecieron los archivos de la ciudad y prácticamente toda la información relativa al Consulado.

La importancia comercial de San Sebastián venía de lejos pero, situándonos en el siglo XVIII cabe mencionar la fundación, en 1728, de La Real Compañía Guipuzcoana de Caracas, que consiguió el monopolio comercial con Venezuela. El Consulado apoyó la creación de esta compañía con la idea de favorecer el comercio de la ciudad y de la provincia.

21 «Al parecer, fue construido sobre las ruinas de una antigua fortaleza. Se atribuye a Sancho el Mayor, rey de Pamplona, la construcción de una primera atalaya defensiva y la primitiva cerca o muralla. Hacia 1194, con posterioridad a la existencia de la citada atalaya, Sancho el Fuerte, rey de Navarra, levantó una cerca militar, que sirviera de fortificación a la recién fundada población donostiarra y al castillo previamente erigido».

www. Euskomedia.org/aunamendi/26806. Auñamendi Eusko Entziklopedia.

22 «En la cúspide del monte Arrobi se yergue ya el torreón del faro construido por el Consulado donostiarra en 1778, detalle este último que nos indica que Paret pintó su cuadro en el intervalo de los veinte años que median entre dicha fecha y su muerte, acaecida en 1799». (KM), Op. Cit., pág..67.

23 «El Ayuntamiento donostiarra y el Consulado estuvieron asentados en el edificio de la lonja, hoy el Museo Naval de la ciudad.». ASTIAZARAIN ACHABAL, María Isabel, El Consulado de San Sebastián y los proyectos de ampliación de su puerto en el siglo XVIII, San Sebastián, Fundación Kutxa, 1998, pág. 123. 
El Consulado lo componían comerciantes marítimos y patrones de barcos, muy interesados en fomentar el comercio marítimo y la navegación. Los dirigentes del Consulado eran conscientes de que para lograr un prospero comercio era necesario regenerar los caminos y los puertos. Como se postulaba desde los ámbitos ilustrados, la mejora de las vías de comunicación, terrestres y marítimas serviría para avanzar en el desarrollo económico y en definitiva en el progreso.

Con ese fin, el Consulado desarrolló la idea de ampliación del puerto donostiarra. Este proyecto se inició en 1770 , tenía como finalidad la mejora de las comunicaciones y de las infraestructuras de la ciudad. Fue el ingeniero Julián Sánchez Bort el encargado de realizar el proyecto de ampliación del puerto, aunque en un inicio, el encargo se hizo a Pedro Ignacio de Lizardi. El proyecto iniciado por Lizardi no se llevó a cabo y fue continuado por Sánchez Bort pero, el proyecto de éste tampoco llegó a realizarse. La idea de la ampliación del puerto tenía como objetivo aumentar la capacidad de acogida del puerto donostiarra para buques de gran tamaño, que en general eran los que utilizaba la compañía de Caracas. Además, se quería mejorar la seguridad marítima y evitar los terribles naufragios que provocaban grandes pérdidas humanas y de mercancías.

Carlos III tuvo conocimiento del interés que había en el País Vasco por la mejora y modernización de sus puertos. De hecho, el rey recibió la petición de aprobación del proyecto del puerto de San Sebastián en, 1773, aprobándolo en agosto del mismo año ${ }^{24}$.

Sánchez Bort era uno de los ingenieros marítimos más importantes de España en ese momento. Ya había trabajado para entonces en la obra del Arsenal de El Ferrol. El proyecto de ampliación que realizó para el puerto de San Sebastián incluía una dársena, diques, muelles, un astillero y un faro en el monte Igueldo ${ }^{25}$. San Sebastián ya contaba con una linterna en Urgull en el castillo de La Mota, pero Sánchez Bort decidió construir un faro en Igueldo. El faro sobre el monte Igueldo fue la única obra que se llevó a cabo de todo el proyecto de Sánchez Bort.

Volviendo al análisis de la pintura, el cronista de la época se lamentaba de que el ayuntamiento no impulsara la realización, por parte de pintores locales, de copias de alguno de los cuadros expuestos con la idea de decorar los muros de las distintas dependencias consistoriales. Como precedente, cita la copia realizada por Ignacio Ugarte del cuadro de Martínez del Mazo que representaba la llegada de Felipe IV a San Sebastián.

24 «...el 15 de agosto desde San Ildefonso, se expedía la Facultad Real firmada por el marqués de Grimaldi. Fueron tres las cuestiones que el monarca consideraría: el comercio, del que juzgaba dependiente la felicidad del reino; la seguridad de las embarcaciones en las tempestades, y por último el que la obra sería financiada por el Consulado.», Ídem, pág. 38.

25 «Constaba (el plan) de una introducción y cinco capítulos, basados en la manufactura de una linterna, la dársena, construcción de los muelles, la muralla interior frente a la ciudad; y el proyecto para mejorar la Concha con: el muelle, diques, astillero, etc..», Ídem, pág. 65. 

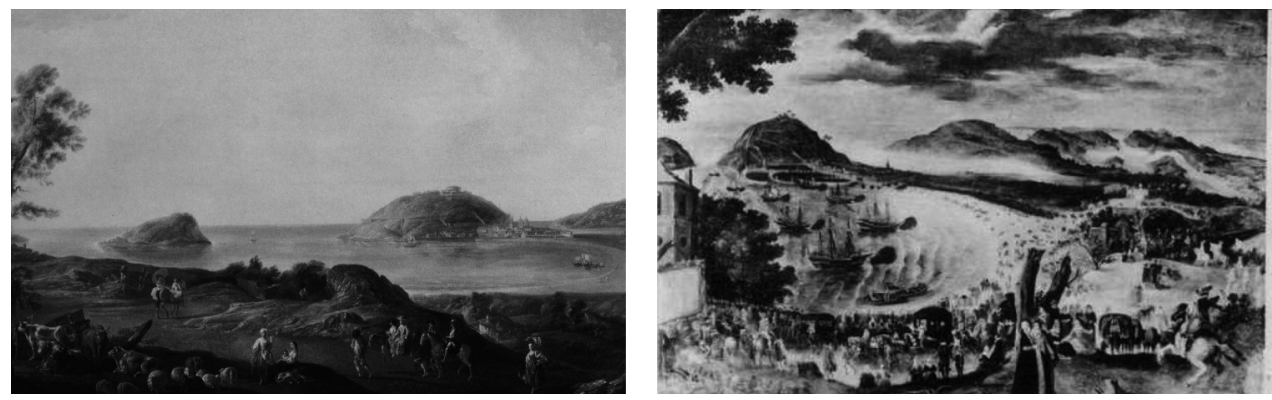

Fig.4. Ignacio Ugarte. (Copia de la obra de Martínez del Mazo, Llegada de Felipe IV a San Sebastián)

Al contemplar ambas obras, la vista de San Sebastián de Paret y la de Martínez del Mazo copiada por Ugarte, se pueden apreciar ciertas similitudes. ¿Conocería Paret esta obra? No lo sabemos, pero muchos elementos de su vista donostiarra nos la hacen recordar. La composición es similar; la bahía de la Concha sirve de escenario para representar la escena principal, muy abigarrada en la de Mazo, algo menos en la de Paret. En los dos cuadros, el desarrollo de la escena con figuras se encuentra en la parte inferior y en cuanto al paisaje se representa la bahía en toda su amplitud, con la isla, Urgull y Ulía; y en ambas imágenes, las ramas de un árbol que asomándose por la izquierda se recortan en el cielo.

Difiere la obra de Paret en la situación muy baja del horizonte, recurso que utiliza habitualmente para reservar amplias zonas de cielo. En la copia de Ugarte, el horizonte se sitúa sin embargo bastante más alto, ya que necesita más espacio para la bahía, que llena de embarcaciones. Esta obra, representa la llegada a San Sebastián del Rey Felipe IV y de la Infanta María Teresa de Austria, con motivo del casamiento de ésta con Luis XIV, establecido en el tratado de los Pirineos.

Siguiendo con las vistas paretianas, es probable que las guipuzcoanas (San Sebastián, Pasajes y Fuenterrabia) fueran realizadas en el estudio a partir de los apuntes y bocetos que tomó en un viaje que realizó a Guipúzcoa entre el verano y el otoño de 1786. Este viaje resultó desafortunado para el pintor ya que tuvo un desgraciado accidente en el que se quemó la mano derecha.

Como es habitual en las panorámicas de su serie, Paret coloca en esta vista de SanSebastián las figuras en la parte baja del cuadro. En este caso gran parte de las figuras incluidos los animales miran en la misma dirección, de derecha a izquierda, lo que intensifica la sensación de movimiento. El cielo ocupa gran parte de la obra. El momento parece ser el del atardecer ya que a la izquierda los tonos anaranjados inducen a pensar en la puesta del sol. En este foco de luz se recorta un árbol que recibe los reflejos del sol de la tarde y adquiere un tono dorado. Las luces y las sombras del terreno del primer término también utilizan los dorados y ocres para indicar la luz de atardecer. 
Si Paret realizó esta obra en el estudio, supo trasladar al lienzo los efectos lumínicos y cromáticos contemplados en el paisaje, logrando un color ambiental que junto con las alargadas sombras identifica perfectamente el momento del atardecer. La gradación tonal que va desde los ocres verdosos de la parte baja que en ascenso se van aclarando y tiñendo de azul, finalizan en un cielo de gran luminosidad y claridad, en el que los naranjas de la izquierda dan calidez al conjunto ${ }^{26}$.

Paret elabora una preciosa escena llena de vida, con figuras de gran dinamismo, realizadas con un extraordinario dibujo y gran lujo de detalles, describiendo objetos, trajes y telas con gran maestría. Utiliza un horizonte bajo lo que le permite reservar gran parte del lienzo para el cielo cuya limpieza y luminosidad contribuyen a dotar de armonía cromática a todo el conjunto.

Se trata de una obra de gran riqueza en matices de color, de composición equilibrada, escenográfica, suntuosa en la que destacan los contrastes lumínicos y la levedad de los personajes. Paret ofrece una pintura narrativa en la que refleja la dualidad de la sociedad del momento. Por un lado, fiel a su estilo rococó, representa escenas frívolas de la clase privilegiada que disfruta de la vida, en este caso las damas y caballeros que se pasean a caballo y, compartiendo un mismo espacio, muestra a otra parte de la sociedad que realiza las labores cotidianas del cuidado del ganado.

Esta vista panorámica desarrolla de forma narrativa una escena envuelta en la atmósfera del paisaje y se convierte en documento pictórico que relata un momento de la vida cotidiana de la ciudad de gran valor historiográfico. Al igual que en otras vistas de la serie, mezcla escenas campesinas protagonizadas por gentes del pueblo con personajes de la aristocracia o de la clase acomodada, incluyendo escenas costumbristas que son el reflejo de una época y de una forma de vida.

Con respecto a esta vista de San Sebastián, existe la hipótesis de que en su día Paret pudiera haber pintado dos vistas de esta ciudad ya que cuando el 20 de noviembre de 1786 realizó el envió a la Corte, mencionaba las vistas de San Sebastián en plural. Esta hipótesis se refuerza con el hecho de que tanto para Fuenterrabia como para el Arenal bilbaíno pintó dos vistas. Además en la vista de San Sebastián que se conoce no pintó propiamente el puerto sino una panorámica de la bahía. Esta posibilidad es defendida por Javier González de Durana, argumentando esta hipótesis en el hecho de que en las otras vistas dobles, Paret dedica una de ellas a la labor portuaria y la otra a describir el paisaje ${ }^{27}$.

\footnotetext{
${ }^{26}$ Véase para la descripciones de las obras, Luis Paret y Alcázar y los puertos del País Vasco, Bilbao, Museo de Bellas Artes de Bilbao, 1996.

${ }^{27}$ «Quizás decidiera, como en Fuenterrabía, realizar dos vistas, una (...) muy paisajística, (...) y otra más cerrada, naviero-laboral y urbana. En ningún caso parece razonable suponer que al referirse Paret a «Las vistas de San Sebastián» incluyera entre ellas la de Pasajes y las de Fuenterrabía. Cabe suponer por tanto que existe (o existió) otra vista de San Sebastián, contemplada la ciudad desde un punto más próximo a sus murallas o a su puerto.». GONZALEZ DE DURANA, Javier, Catálogo en Luis Paret y Alcázar 1746-1799, Vitoria, Servicio Central de Publicaciones del Gobierno Vasco, 1991, pág. 244.
} 


\section{CONCLUSIÓN}

El estudio sobre la pintura española de la segunda mitad del siglo XVIII se ha centrado fundamentalmente en la obra del gran maestro Goya. Se puede decir que queda mucho por investigar sobre los pintores contemporáneos al genial artista de Fuendetodos y en especial sobre la figura de Paret y Alcázar. Si a ello añadimos el hecho de que gran parte de las obras de Paret se encuentran en manos privadas, lo que dificulta su estudio, podemos decir que queda mucho por saber y que son muchas las incógnitas sin responder sobre este gran artista.

Para futuras investigaciones resulta interesante la expectativa de la posible existencia de obras de Paret desconocidas hasta el momento, relacionadas con la serie de puertos. ¿De verdad existieron? ¿Qué pueblos o ciudades fueron representados? ¿Pudo pintar puertos de todo el mar Cantábrico, desde el País Vasco hasta Galicia? ¿A qué colecciones pertenecieron? Son preguntas que se podrán responder si algún día se localizan los cuadros que supuestamente pintó Paret. La localización de esas obras permitiría tener una visión más completa de la serie de puertos de la mar Océana 
